\title{
Chymotrypsin Protein Cleavage Reagent
}

National Cancer Institute

\section{Source}

National Cancer Institute. Chymotrypsin Protein Cleavage Reagent. NCI Thesaurus. Code C161883.

A protein cleavage reagent comprised of the serine proteinase chymotrypsin that cleaves proteins into peptides at the C-terminal side of a phenylalanine, tyrosine, tryptophan or leucine residue unless that residue is followed by a proline. 